\title{
Molecular docking, 3D-QSAR and structural optimization on imidazo-pyridine derivatives dually targeting AT1 and PPAR $\gamma$
}

\author{
Jun Zhang ${ }^{1}$, Qing-Qing Hao ${ }^{1}$, Xin Liu ${ }^{1}$, Zhi Jing ${ }^{1}$, Wen-Qing Jia ${ }^{1}$, Shu-Qing Wang ${ }^{1}$, \\ Wei-Ren Xu' ${ }^{2}$, Xian-Chao Cheng ${ }^{1}$, Run-Ling Wang ${ }^{1}$ \\ ${ }^{1}$ Tianjin Key Laboratory on Technologies Enabling Development of Clinical Therapeutics and Diagnostics (Theranostics), \\ School of Pharmacy, Tianjin Medical University, Tianjin 300070, China \\ ${ }^{2}$ Tianjin Key Laboratory of Molecular Design and Drug Discovery, Tianjin Institute of Pharmaceutical Research, Tianjin \\ 300193, China \\ Correspondence to: Xian-Chao Cheng, email: chengxianchao@aliyun.com \\ Run-Ling Wang, email: wangrunling@tmu.edu.cn
}

Keywords: imidazo- \pyridines, ATI, PPARY, molecular docking, 3D-QSAR

Received: December 20,2016 Accepted: January 27, $2017 \quad$ Published: February 28, 2017

Copyright: Zhang et al. This is an open-access article distributed under the terms of the Creative Commons Attribution License (CC-BY), which permits unrestricted use, distribution, and reproduction in any medium, provided the original author and source are credited.

\section{ABSTRACT}

Telmisartan, a bifunctional agent of blood pressure lowering and glycemia reduction, was previously reported to antagonize angiotensin II type 1 (AT1) receptor and partially activate peroxisome proliferator-activated receptor $\gamma$ (PPAR $\gamma$ ) simultaneously. Through the modification to telmisartan, researchers designed and obtained imidazo-\pyridine derivatives with the $\mathrm{IC}_{50} \mathrm{~s}$ of $0.49 \sim 94.1 \mathrm{nM}$ against AT1 and $\mathrm{EC}_{50}$ s of $20 \sim 3640 \mathrm{nM}$ towards PPAR $\gamma$ partial activation. For minutely inquiring the interaction modes with the relevant receptor and analyzing the structure-activity relationships, molecular docking and 3D-QSAR (Quantitative structure-activity relationships) analysis of these imidazo-\pyridines on dual targets were conducted in this work. Docking approaches of these derivatives with both receptors provided explicit interaction behaviors and excellent matching degree with the binding pockets. The best CoMFA (Comparative Molecular Field Analysis) models exhibited predictive results of $q^{2}=0.553, r^{2}=0.954, S E E=0.127, r^{2}$ pred $=0.779$ for AT1 and $q^{2}=0.503, r^{2}=1.00$, SEE $=0.019, r^{2}$ pred $=0.604$ for PPAR $\gamma$, respectively. The contour maps from the optimal model showed detailed information of structural features (steric and electrostatic fields) towards the biological activity. Combining the bioisosterism with the valuable information from above studies, we designed six molecules with better predicted activities towards AT1 and PPARy partial activation. Overall, these results could be useful for designing potential dual AT1 antagonists and partial PPARY agonists.

\section{INTRODUCTION}

Type 2 diabetes mellitus (T2DM) was thought to result from the combination of genetic factor, such as lifestyle changing, population aging, exercise reducing [1,2]. It is predicted that the number of people with this disorder will be increasing without highly efficient therapy $[3,4]$. In addition, diabetes mellitus was thought to exhibit some relationship with hypertension. The incidence of hypertension occurring to patients with diabetes mellitus is almost twice higher than those with no diabetes mellitus. The greater mortality of patients in diabetes mellitus right attributed to cardiovascular diseases, among which hypertension takes up to high proportion of $75 \%$ [5]. So, developing novel and potent agents to concurrently treat hyperglycemia and hypertension with high occurrence allows of no delay.

Telmisartan, which antagonized angiotensin II type-1 receptor (AT1R), was a novel oral agent for blood pressure reducing and cardiovascular protection [6]. Previously, it was reported to display dual activities of antagonizing AT1 and partially activation towards PPAR $\gamma$ [7-9].

The peroxisome proliferator-activated receptors $(\alpha, \delta$ and $\gamma$ ) belong to the nuclear hormone receptor superfamily that regulate the expression of target genes 
$[10,11] . \operatorname{PPAR} \gamma$, the most thoroughly studied isoform in the treatment of metabolic syndrome [12], is widely expressed in adipose tissue, macrophages, liver, kidney and lung [13]. The binding of active ligands to PPAR $\gamma$ would modulate the expression of related genes, play vital role in lipogenesis, glycolipids metabolism and immune system [14]. Thiazolidinediones (TZDs, such as rosiglitazone and piglitazone) can greatly activate PPAR $\gamma$. TZDs were first reported as insulin-sensitizing drugs in the early 1980 s by the pharmaceutical company Takeda and developed for the treatment of type 2 diabetes mellitus in clinical practice [15-17]. However, the administration of TZDs could produce severe side effects such as fluid retention, weight gain, cardiac hypertrophy, bone fractures, and hepatotoxicity [18]. As reported in 2007 by Nissen and Wolski, rosiglitazone was removed from the European market due to its association with excessive cardiovascular risk $[12,19,20]$.

Renin-angiotensin system (RAS) has reported to exhibit significant roles in reducing blood pressure and maintaining electrolyte and fluid homeostasis. Angiotensin receptor included in this system is a hypertension-related $\mathrm{G}$ protein-coupled receptor (GPCR) [21]. There are two main types: AT1 and angiotensin II type-2 receptor (AT2), among which the former receives the most research [22]. The bio-effects of angiotensin II (Ang II), such as vasoconstriction, the increase of vasopressin secretion and myocardial hypertrophy, are primarily developed via the activation of AT1 while activating AT2 will inhibit cell growth and lead to cell differentiation and apoptosis [2325]. AT1 receptor blockers (ARBs), namely sartans, which enable to block the action of AT1 receptor, were developed to treat unfavorable symptoms [9, 26, 27].

As summarized in Figure 1, PPAR $\gamma$ closely correlated with RAS (rennin-angiotensin system). The mutation of PPAR $\gamma$ would induce the enhanced expression of AT1R, leading to an increase of Ang II. As a result, the following reactive oxygen species cause hypertension symptom. Fortunately, the reported PPAR $\gamma$ agonists like TZDs could activate PPAR $\gamma$ as well as block its mutation, thus interrupting the following process just as the role of small interfering RNA and AT1R blockers [28].

In order to find novel drugs with dual AT1 antagonism and partial PPAR $\gamma$ activation activities, the structure of telmisartan (Figure 2) could be modified to retain the AT1 receptor antagonistic activity and enhance the partially PPAR $\gamma$ agonistic activity. Series of imidazo[4,5-b]pyridines and imidazo[4,5-c]pyridin-4-one derivatives (Figure 2) were obtained by Agustin Casimiro-Garcia [17, 29] via maintaining the main scaffold of telmisartan. These compounds showed robust AT1 antagonistic activity and partial activation of PPAR $\gamma$. Their activities were evaluated with the $\mathrm{IC}_{50} \mathrm{~s}$ of $0.49 \sim 94.1 \mathrm{nM}$ against AT1 and $\mathrm{EC}_{50} \mathrm{~s}$ of 20 3640 nM for PPAR $\gamma$ partial activation.

For the purpose of minutely determining the binding mode and structure-activity relationship (SAR) of these molecules, docking and CoMFA (Comparative Molecular Field Analysis) studies were conducted in

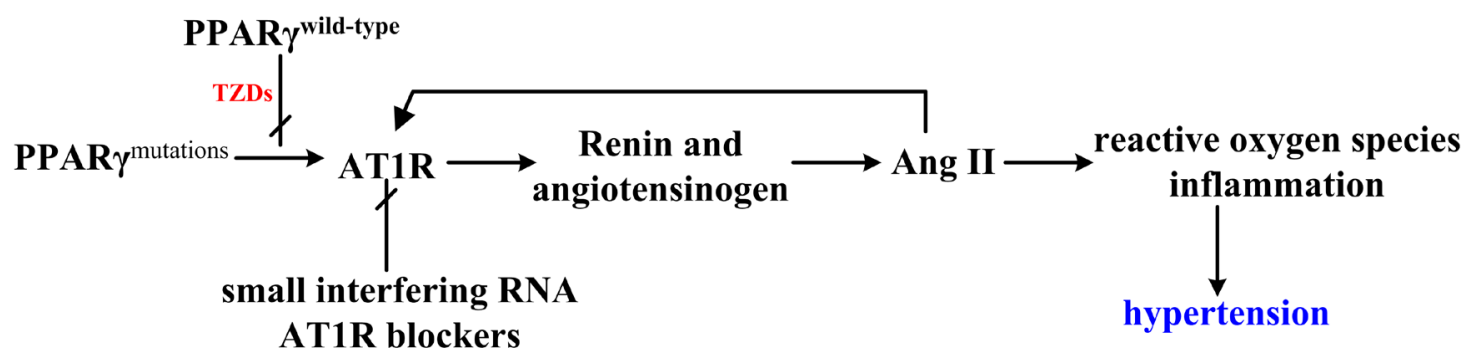

Figure 1: The closely relationship between PPAR $\gamma$ and RAS (rennin-angiotensin system). As shown, PPAR $\gamma$ mutations would increase the expression of AT1 receptor, thus leading to hypertension through produced reactive oxygen species (ROS) and inflammation. However, treatment of TZDs, small interfering RNA and AT1R blockers will interrupt this effect by interfering different phases.

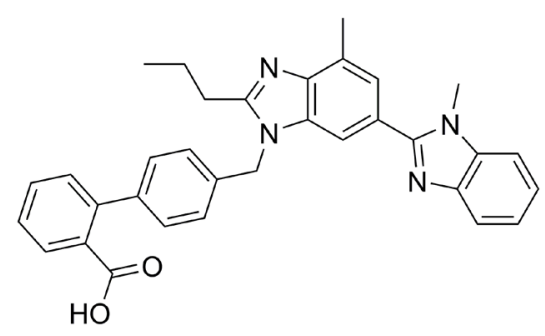

telmisartan

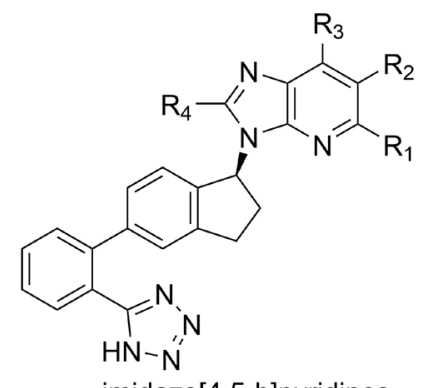

imidazo[4,5-b]pyridines

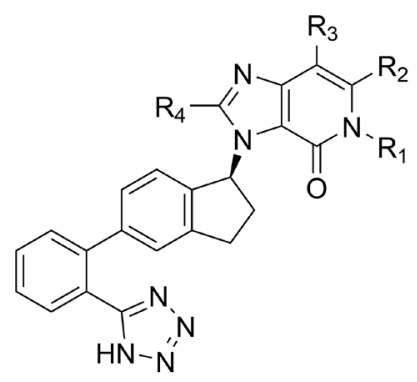

imidazo[4,5-c]pyridin-4-one derivatives

Figure 2: Structural scaffolds of imidazo[4,5-b]pyridines and imidazo[4,5-c]pyridin-4-one derivatives modified from telmisartan. 
our work. Wholly, these results from the computational techniques could be useful for designing potential dual AT1 antagonists and PPAR $\gamma$ partial agonists.

\section{RESULTS AND DISCUSSION}

\section{Molecular docking}

For a deep insight into the crucial interactions of molecules with AT1 and PPAR $\gamma$, these imidazo- $\backslash$ pyridine derivatives (Table 1) were docked into the protein's binding site using standard-precision (SP) docking tool [30]. As presented in Figure 3, the fascinating illustrations of ligands (8 and telmisartan) with AT1 pocket could be of great help to understand the binding mechanism. The whole structural skeletons of both molecules were appropriate for the pocket environment. The representative compound 8 superimposed perfectly with telmisartan in the binding surface, especially the hydrophobic moiety as well as the parts of hydrogen donors and acceptors, which validated the similar modes to telmisartan. Additionally, telmisartan matched better with the receptor surface compared with compound 8 , illustrating the higher AT1 antagonistic activity than 8 . This was mainly derived from the different $\mathrm{R}$ substituent in structures, which led to some divergence in position or orientation in the binding surface. As to the detailed interactions in AT1 pocket, the critical hydrogen bonds of compound 8 with residues Tyr35, Arg167 and Lys199 were almost consistent with telmisartan. Both molecules formed $\pi-\pi$ interaction with Trp84 as well. Above-mentioned results from docking analysis verified the bio-activities of these compounds against AT1 receptor.

Seen from Figure 4A, compound 8, 19 and cocrystallized ligand 1 matched well in PPAR $\gamma$ binding surface. As $\mathrm{R}_{1}$ substituent was radically diverse, the orientation of this part in the surface was somewhat inconsistent with each other. The $\mathrm{R}_{1}$ part of compound 19 obviously extended to the narrow pocket, so compound 19 was in perfect accordance with PPAR $\gamma$ pocket in comparison to 1 and 8 , validating its higher agonistic activity. Therefore, a proper modification to $R_{1}$ will probably be beneficial to the PPAR $\gamma$ partial activity, such as increasing the substituent, extending the carbon chain.

Unexpectedly in PPAR $\gamma$ interaction modes, the lipophilic tails $\left(\mathrm{R}_{1}\right)$ of 1,8 and compound 19 were buried in AF-2 domain of the binding pocket, interacting with residues His323, Tyr327 and His449 through non-polar or van der Waals interactions as indicated in previous paper $[17,29]$. Clearly, their interaction modes were substantially distinct from the typical PPAR $\gamma$ agonists, whose acid heads directly interacted with His 323 , Tyr327 and His449. Although the acidic tetrazole ring of 1,8 and 19 bound well in similar orientation, their binding behavior in the active site displayed some different. The $\mathrm{N}-2$ of tetrazole ring in molecule 1 and 8 interacted with
Arg288 through forming an H-bond while 19 formed another $\mathrm{H}$-bond between the $\mathrm{N}-1$ of tetrazole and $\mathrm{NH}$ of Ser342, which was mainly due to the structural flexibility.

\section{CoMFA statistical analysis}

\section{AT1 model}

The CoMFA model was derived using a training set of 26 imidazo- $\backslash$ pyridines including 10 imidazo[4,5-b] pyridines and 15 imidazo[4,5-c]pyridin-4-one derivatives with telmisartan as the template. The test set including five molecules was to validate the external predictive power of the CoMFA model. The predictive and residual values of the dataset were mentioned in Table 2, and other statistical results from the best model were listed in Table 3.

As shown in Table 3, the cross-validated correlation coefficient $\mathrm{q}^{2}$ through LOO method was 0.553 and the number of optimal components was 3 . With the observed optimal ONC, the favorable conventional correlation coefficient $\mathrm{r}^{2}$ (0.954), SEE (0.127) and $\mathrm{F}$ value (117.807) from no validation method implied a highly qualified and robust CoMFA model. Figure 5 illustrated an excellent agreement between the actual $\mathrm{pIC}_{50} \mathrm{~s}$ and the predicted values of the training set (Figure 5A) and the test set (Figure 5C). Nevertheless, the predicted correlation coefficient $r^{2}$ pred $(0.779)$ from the test set confirmed the CoMFA model to be highly predictive. The distributions for steric and electrostatic fields were $61.9 \%$ and $38.1 \%$, respectively, suggesting a higher steric contribution to AT1 antagonistic activity than electrostatic field.

\section{PPAR $\gamma$ model}

A training set of 21 imidazo- $\backslash$ pyridines and a test set of five other derivatives were employed to construct and validate the CoMFA model, respectively. The statistical data were summarized in Table 2 and Table 3 . PLS method yielded the terms of $\mathrm{q}^{2}(0.503)$ with ten principal components, $\mathrm{r}^{2}(1.00)$, SEE (0.019) and $\mathrm{F}$ value (2107.933). Similarly to AT1, steric field (75.4\%) was found to exhibit an absolutely higher contribution towards PPAR $\gamma$ partial agonism compared to the electrostatic field $(24.6 \%)$. The linear regression curve portrayed in Figure $5 \mathrm{D}\left(\mathrm{r}_{\text {pred }}^{2}=0.604\right)$ along with the $\mathrm{q}^{2}$ value $(>0.6)$ implied the CoMFA model to be relatively robust and stable.

The satisfactory statistical results demonstrated the predictivity and accuracy of the CoMFA models (AT1 and PPAR $\gamma$ ). The qualified models could be used in further study to evaluate and design novel imidazo- $\backslash$ pyridine derivatives with potential AT1 antagonism and PPAR $\gamma$ partial activation.

\section{The StDev*Coefficient CoMFA contour maps}

The contour plots of the steric and electrostatic fields observed from the best CoMFA models of both targets were depicted in Figures 6-9. The type of 
Table 1: Structures and bioactivities $\left(\mathrm{AT} 1-\mathrm{IC}_{50}\right.$ and $\left.\mathrm{PPAR} \gamma-\mathrm{EC}_{50}\right)$ of imidazo- $\backslash$ pyridine derivatives from available literatures $[17,29]$

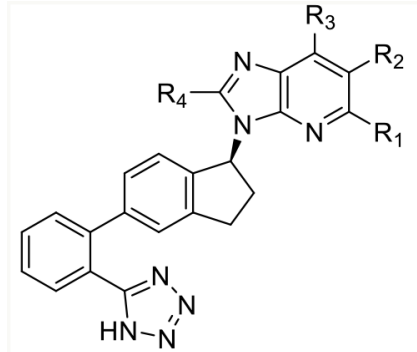

imidazo[4,5-b]pyridines (01-10)

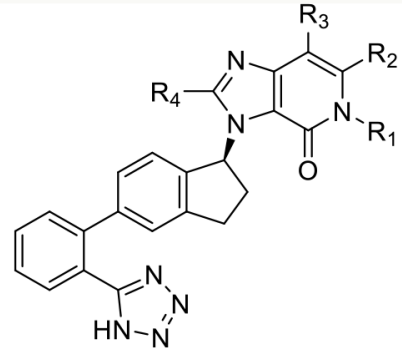

imidazo[4,5-c]pyridin-4-ones (11-25)

\begin{tabular}{|c|c|c|c|c|c|c|}
\hline No. & $\mathbf{R}_{1}$ & $\mathbf{R}_{2}$ & $\mathbf{R}_{3}$ & $\mathbf{R}_{4}$ & $\begin{array}{c}\text { AT1 } \\
\mathrm{IC}_{50}(\mathrm{nM})\end{array}$ & $\begin{array}{c}\text { PPAR } \gamma \\
\text { EC }_{50}(\mathrm{nM})\end{array}$ \\
\hline Telmisartan & & & & & 0.49 & 1520 \\
\hline 1 & & $\mathrm{H}$ & & & 7.6 & 591 \\
\hline 2 & & $\mathrm{H}$ & & & 13.3 & 1320 \\
\hline 3 & & $\mathrm{H}$ & & & 10.2 & 295 \\
\hline 4 & & $\mathrm{H}$ & & & 8.2 & 762 \\
\hline 5 & & & & & 15.7 & 1340 \\
\hline 6 & & $\mathrm{H}$ & & & 6.8 & 494 \\
\hline 7 & & $\mathrm{H}$ & s & & 16.9 & 264 \\
\hline 8 & & $\mathrm{H}$ & & & 1.6 & 212 \\
\hline 9 & & $\mathrm{H}$ & & & 3.5 & 89 \\
\hline 10 & & $\mathrm{H}$ & $\xi$ & & 5.2 & 90 \\
\hline 11 & & $\mathrm{H}$ & $\mathrm{H}$ & & 12.7 & 292 \\
\hline 12 & & $\mathrm{H}$ & $\mathrm{H}$ & & 19.8 & 1250 \\
\hline
\end{tabular}




\begin{tabular}{|c|c|c|c|c|c|c|}
\hline No. & $\mathbf{R}_{1}$ & $\mathbf{R}_{2}$ & $\mathbf{R}_{3}$ & $\mathbf{R}_{4}$ & $\begin{array}{c}\text { AT1 } \\
\text { IC }_{50}(\mathrm{nM}) \\
\end{array}$ & $\begin{array}{c}\text { PPAR } \gamma \\
\mathrm{EC}_{50}(\mathrm{nM})\end{array}$ \\
\hline 13 & & $\mathrm{H}$ & $\mathrm{H}$ & & 19.4 & 1710 \\
\hline 14 & & $\mathrm{H}$ & $\mathrm{H}$ & & 41 & 942 \\
\hline 15 & & $\mathrm{H}$ & $\mathrm{H}$ & & 37.7 & 103 \\
\hline 16 & & $\mathrm{H}$ & $\mathrm{H}$ & & 5.1 & 97 \\
\hline 17 & & $\mathrm{H}$ & $\mathrm{H}$ & & 13.5 & 685 \\
\hline 18 & & $\mathrm{H}$ & $\mathrm{H}$ & & 94.1 & 187 \\
\hline 19 & & $\mathrm{H}$ & $\mathrm{H}$ & & 29.3 & 20 \\
\hline 20 & & $\mathrm{H}$ & $\mathrm{H}$ & & 67.4 & 159 \\
\hline 21 & & $\mathrm{H}$ & $\mathrm{H}$ & & 36.9 & 108 \\
\hline 22 & & $\mathrm{H}$ & $\mathrm{H}$ & & 63.8 & 3580 \\
\hline 23 & & $\mathrm{H}$ & $\mathrm{H}$ & & 45.2 & 3640 \\
\hline
\end{tabular}

(Continued) 


\begin{tabular}{|c|c|c|c|c|c|c|}
\hline No. & $\mathbf{R}_{1}$ & $\mathbf{R}_{2}$ & $\mathbf{R}_{3}$ & $\mathbf{R}_{4}$ & $\begin{array}{c}\text { AT1 } \\
\text { IC }_{50}(\mathrm{nM}) \\
\end{array}$ & $\begin{array}{c}\text { PPAR } \gamma \\
\text { EC }_{50}(\mathrm{nM}) \\
\end{array}$ \\
\hline 24 & & $\mathrm{H}$ & & & 6.8 & 42 \\
\hline 25 & & $\mathrm{H}$ & & & 7 & 295 \\
\hline
\end{tabular}

$\mathbf{A}$

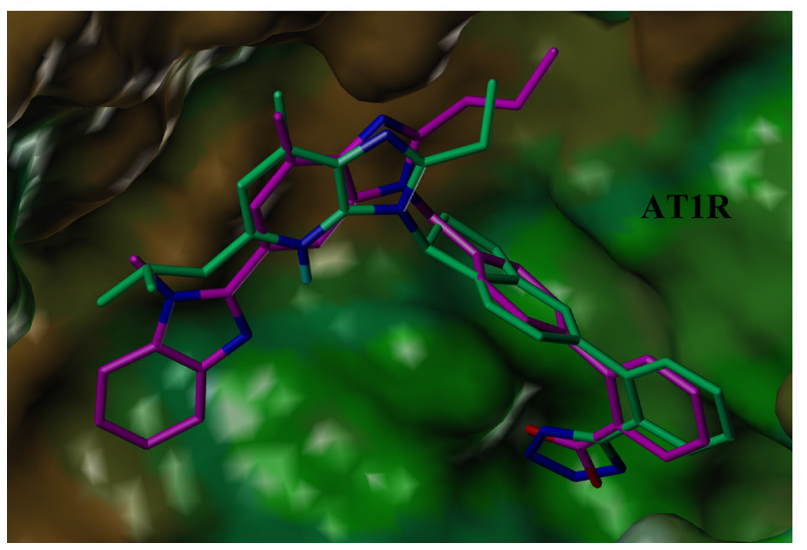

B

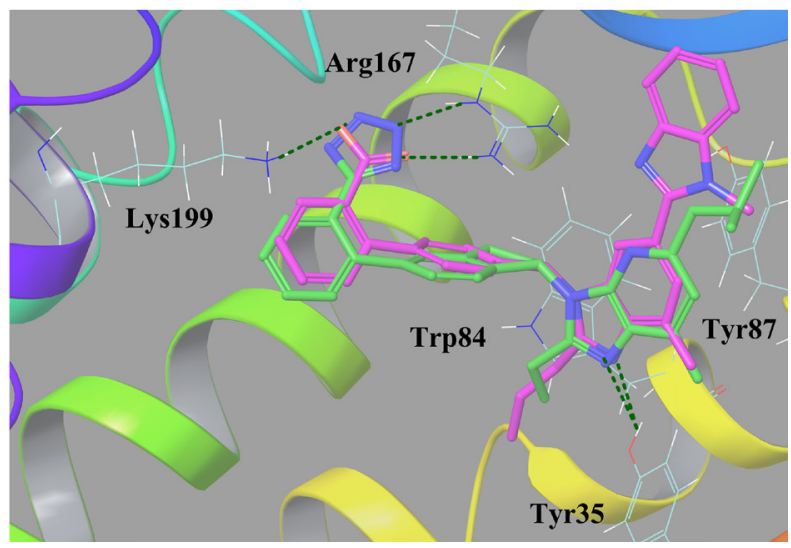

Figure 3: (A) Binding surface of compound 8 (green) and telmisartan (magenta) with AT1 receptor pocket (PDB ID: 4ZUD). (B) Interaction behaviors of compound 8 (green) and telmisartan (magenta) in AT1 receptor active site. H-bond interactions were represented by green dashed line. Telmisartan was regarded as a positive control.

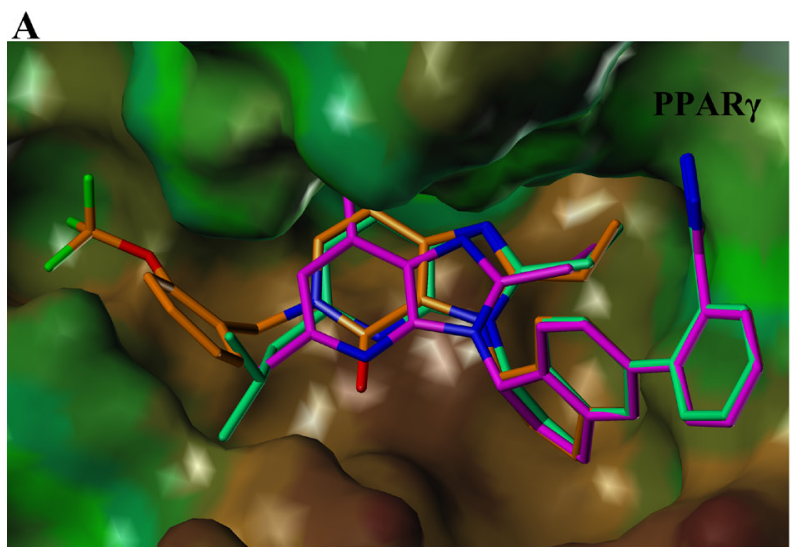

B

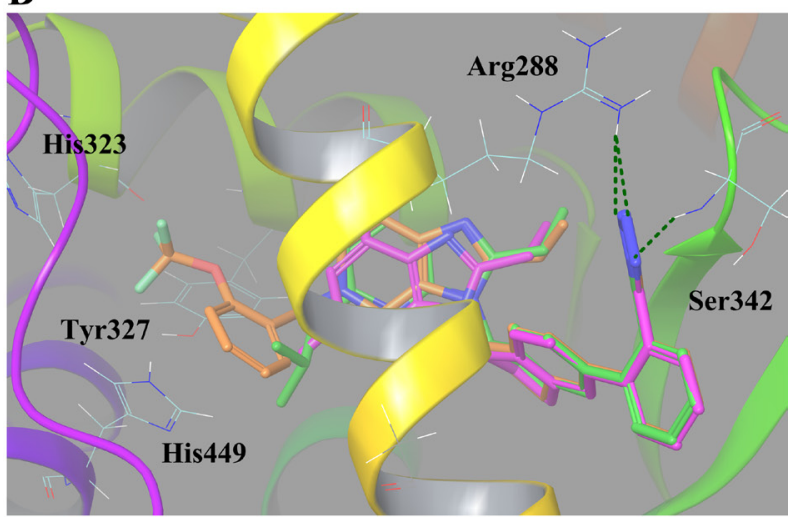

Figure 4: (A) Binding surface of compound 8 (green), 19 (orange) and co-crystallized ligand 1 (magenta) with PPAR $\gamma$ pocket (PDB ID: 3R8A). (B) Interaction behaviors of compound 8 (green), 19 (orange) and co-crystallized ligand 1 (magenta) in PPAR $\gamma$ active site. H-bond interactions were represented by green dashed line. Co-crystallized ligand 1 was regarded as a positive control. 
Table 2: The actual and predictive activity values of the training and test datasets from the best AT1 and PPAR $\gamma$ CoMFA models

\begin{tabular}{|c|c|c|c|c|c|c|}
\hline \multirow{2}{*}{ No. } & \multicolumn{3}{|c|}{ AT1 } & \multicolumn{3}{|c|}{ PPAR $\gamma$} \\
\hline & Actual pIC ${ }_{50}$ & Predicted $\mathrm{pIC}_{50}$ & Residual error & Actual pEC 50 & Predicted $\mathrm{pEC}_{50}$ & Residual error \\
\hline Telmisartan & 0.3098 & 0.222 & 0.0879 & -3.1818 & -3.181 & -0.0008 \\
\hline 1 & -0.8808 & -1.008 & 0.1271 & -2.7716 & -2.781 & 0.0096 \\
\hline 2 & -1.1239 & -1.035 & -0.0888 & -3.1206 & -3.109 & -0.0114 \\
\hline 3 & -1.0086 & -1.051 & 0.0429 & -2.4698 & -2.473 & 0.0032 \\
\hline $4^{\# *}$ & -0.9138 & -0.846 & -0.0678 & -2.8820 & -3.379 & 0.4967 \\
\hline 5 & -1.1959 & -1.117 & -0.079 & -3.1271 & -3.121 & -0.0063 \\
\hline 6 & -0.8325 & -0.873 & 0.0406 & -2.6937 & -2.719 & 0.0252 \\
\hline 7 & -1.2279 & -0.923 & -0.3054 & -2.4216 & -2.404 & -0.0172 \\
\hline 8* & -0.2041 & -0.418 & 0.2141 & -2.3263 & -2.326 & -0.0003 \\
\hline 9 & -0.5441 & -0.496 & -0.0482 & -1.9494 & -1.954 & 0.0049 \\
\hline $10 *$ & -0.7160 & -0.636 & -0.0804 & -1.9542 & -2.572 & 0.6178 \\
\hline $11^{\#}$ & -1.1038 & -1.618 & 0.5142 & -2.4654 & -2.431 & -0.034 \\
\hline $12 *$ & -1.2967 & -1.262 & -0.0344 & -3.0969 & -2.569 & -0.5279 \\
\hline 13 & -1.2878 & -1.363 & 0.0756 & -3.2330 & -3.215 & -0.0179 \\
\hline 14 & -1.6128 & -1.53 & -0.0829 & -2.9741 & -2.985 & 0.0106 \\
\hline 15 & -1.5763 & -1.455 & -0.1217 & -2.0128 & -2.014 & 0.0013 \\
\hline $16^{\#}$ & -0.7076 & -1.41 & 0.7024 & -1.9868 & -2.003 & 0.0166 \\
\hline 17 & -1.1303 & -1.028 & -0.1021 & -2.8357 & -2.842 & 0.0061 \\
\hline 18 & -1.9736 & -2.091 & 0.1173 & -2.2718 & -2.27 & -0.0016 \\
\hline 19 & -1.4669 & -1.466 & -0.0011 & -1.3010 & -1.304 & 0.0035 \\
\hline $20^{\# *}$ & -1.8287 & -1.717 & -0.1117 & -2.2014 & -2.736 & 0.5346 \\
\hline 21 & -1.5670 & -1.675 & 0.1075 & -2.0334 & -2.046 & 0.0128 \\
\hline 22 & -1.8048 & -1.762 & -0.0427 & -3.5539 & -3.564 & 0.0102 \\
\hline 23 & -1.6551 & -1.773 & 0.1175 & -3.5611 & -3.565 & 0.0036 \\
\hline $24^{\#}$ & -0.8325 & -1.325 & 0.4925 & -1.6232 & -1.611 & -0.0125 \\
\hline 25 & -0.8451 & -0.901 & 0.0561 & -2.4698 & -2.464 & -0.0057 \\
\hline
\end{tabular}

\# test set of AT1 model, * test set of PPAR $\gamma$ model.

Table 3: Statistical parameters from the best AT1 and PPAR $\gamma$ CoMFA models

\begin{tabular}{lccc}
\hline \multirow{2}{*}{ Statistical Parameters } & & \multicolumn{2}{c}{ CoMFA } \\
\cline { 3 - 4 } & & AT1 & PPAR $\boldsymbol{\gamma}$ \\
\hline \multirow{2}{*}{ Leave-One-Out(LOO) } & $\mathrm{q}^{2}$ & 0.553 & 0.503 \\
& $\mathrm{ONC}$ & 3 & 10 \\
No validation & $\mathrm{r}^{2}$ & 0.954 & 1.000 \\
& $\mathrm{SEE}$ & 0.127 & 0.019 \\
\multirow{2}{*}{ Field distributions (\%) } & $\mathrm{F}$ value & 117.807 & 2107.933 \\
& $\mathrm{r}_{\text {pred }}^{2}$ & 0.779 & 0.604 \\
& Steric & 61.9 & 75.4 \\
\hline
\end{tabular}

a: the cross-validated correlation coefficient, $\mathrm{q}^{2} ; \mathrm{b}$ : the optimum number of components, ONC; c: the conventional correlation coefficient, $\mathrm{r}^{2}$ : d: standard error of estimate, SEE; e: Fisher Test value; f: the predicted correlation coefficient, $\mathrm{r}^{2}$ pred ${ }^{\circ}$ 

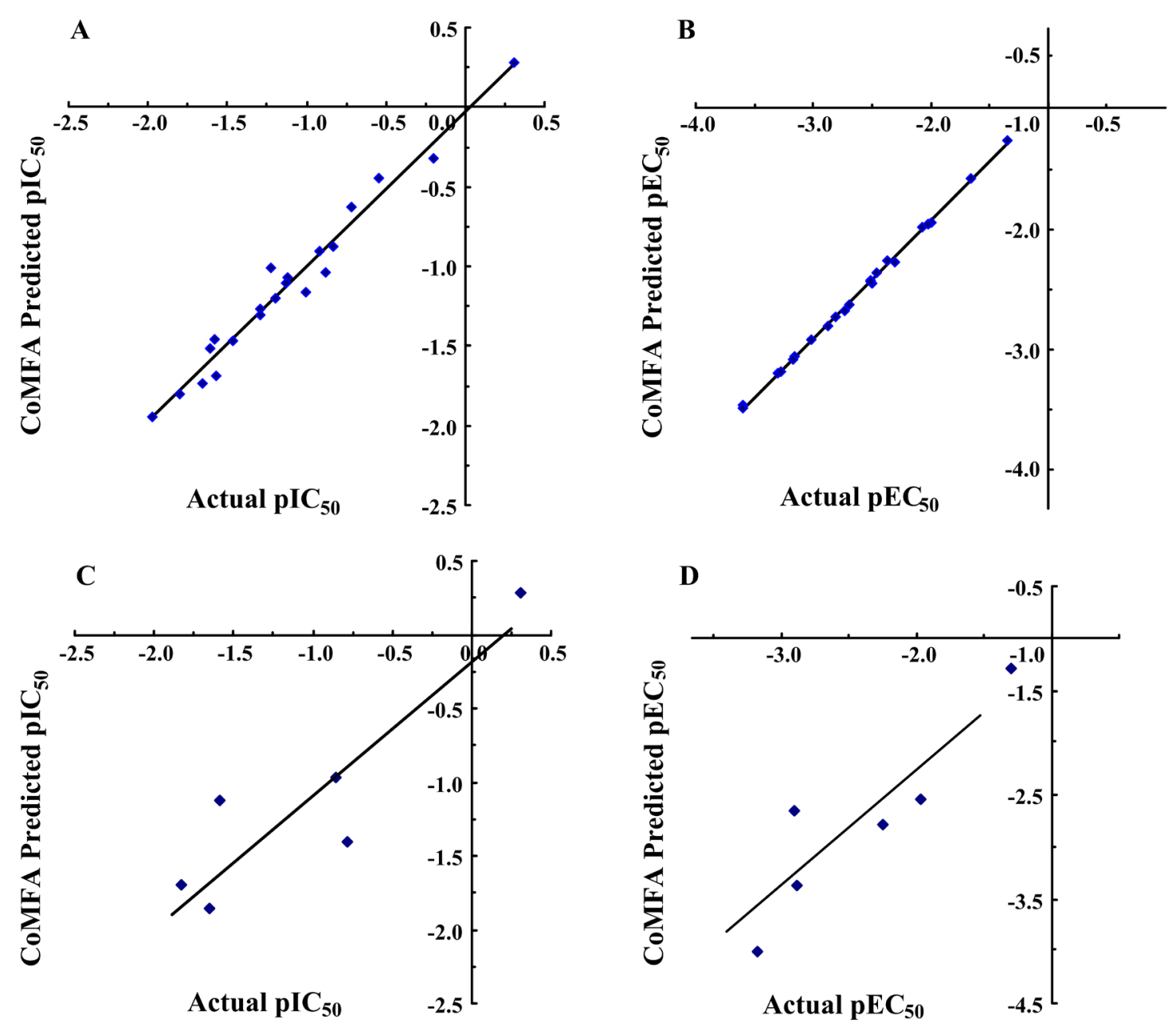

Figure 5: The graphical presentations of the predicted activities versus the actual activities using the best CoMFA models. (A) Fitted prediction for the training set of best AT1 model $\left(\mathrm{r}^{2}=0.954\right)$. (B) Fitted prediction for the training set of best PPAR $\gamma$ model $\left(\mathrm{r}^{2}=1.00\right)$. (C) Fitted prediction for the test set of best AT1 model $\left(\mathrm{r}^{2}\right.$ pred $\left.=0.779\right)$. (D) Fitted prediction for the test set of best PPAR $\gamma$ model $\left(\mathrm{r}^{2}{ }_{\text {pred }}=0.604\right)$.
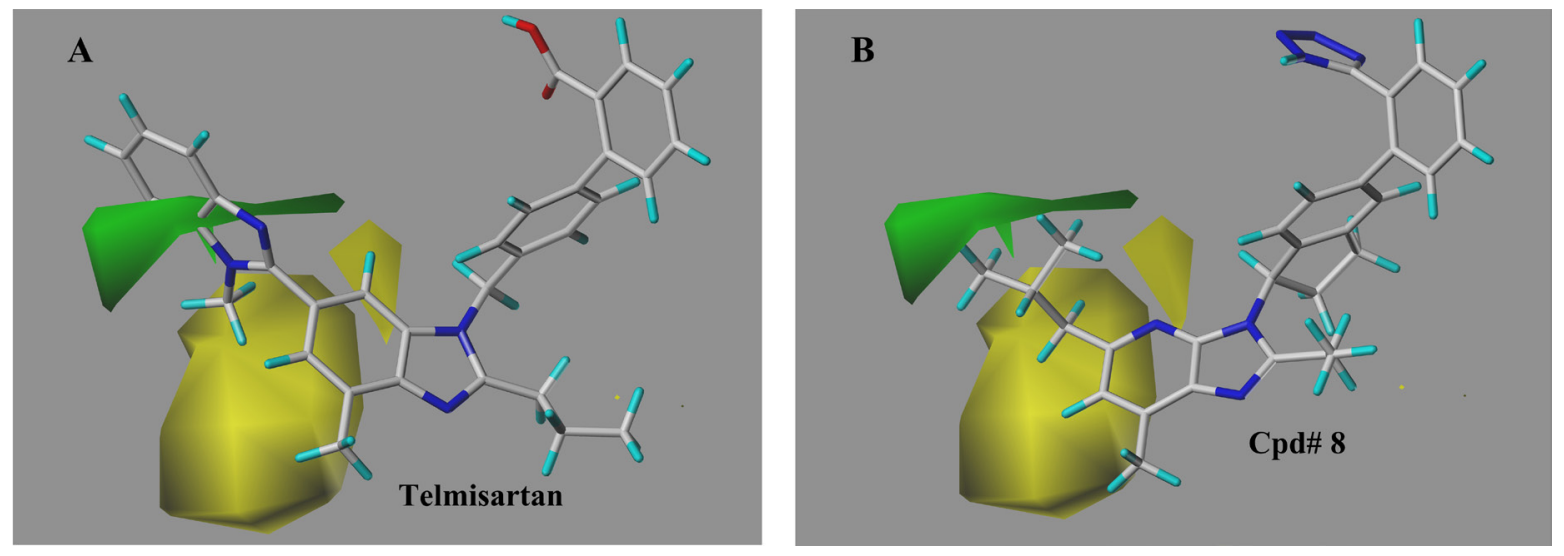

Figure 6: The steric field contour maps of representative compounds from the best CoMFA model (AT1). Green regions referred to higher activity by introducing bulker groups while the yellow parts would lead to increased activity with smaller substituents. (A) telmisartan (the most active molecule), (B) compound 8. 
CoMFA field was regulated to StDev*Coeff (the standard deviation and the coefficient). The field levels for favored and disfavored regions were set to be default $(80.0 \%$ and $20.0 \%$, respectively). In steric field contour maps (Figure 6 and Figure 8), green blocks referred to areas where increasing the steric bulk of one substituent would enhance the activity while yellow areas represented the opposite. Similarly in electrostatic field maps (Figure 7 and Figure 9), blue contours indicated a higher bioactivity by introducing electron-donating groups. The red parts, however, presented that the potency will be improved with the electron withdrawing substituent.
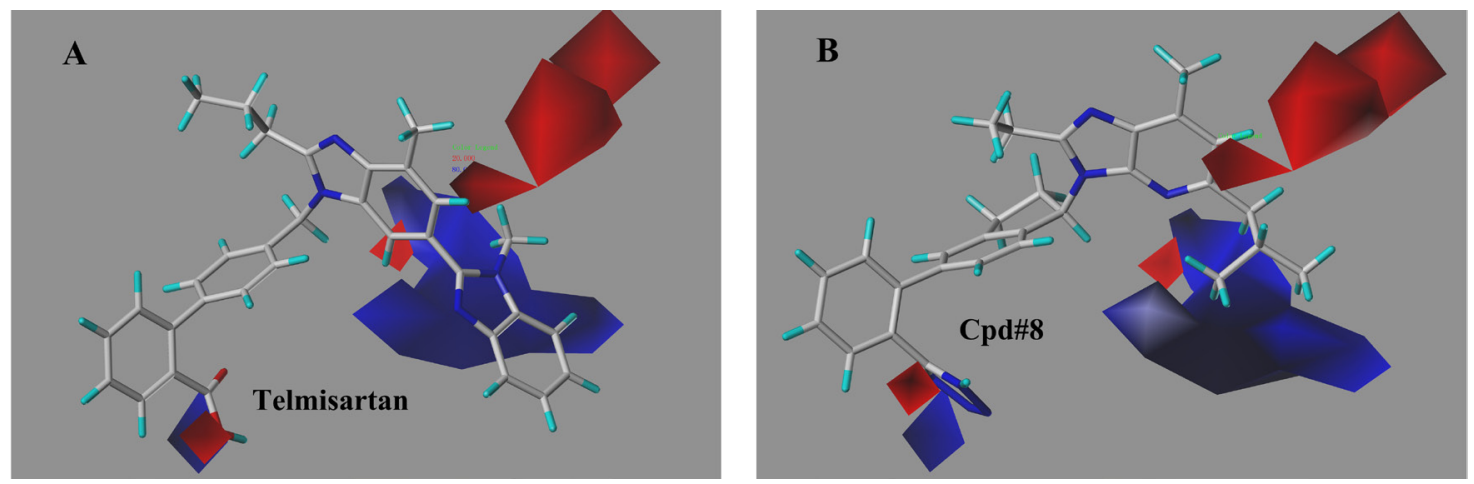

Figure 7: The electrostatic field contour maps of representative compounds from the best CoMFA model (AT1). The blue and red contours respectively indicated that electropositive and electronegative substituents in the corresponding position would lead to increased antagonistic activity. (A) telmisartan (the most active molecule), (B) compound 8.
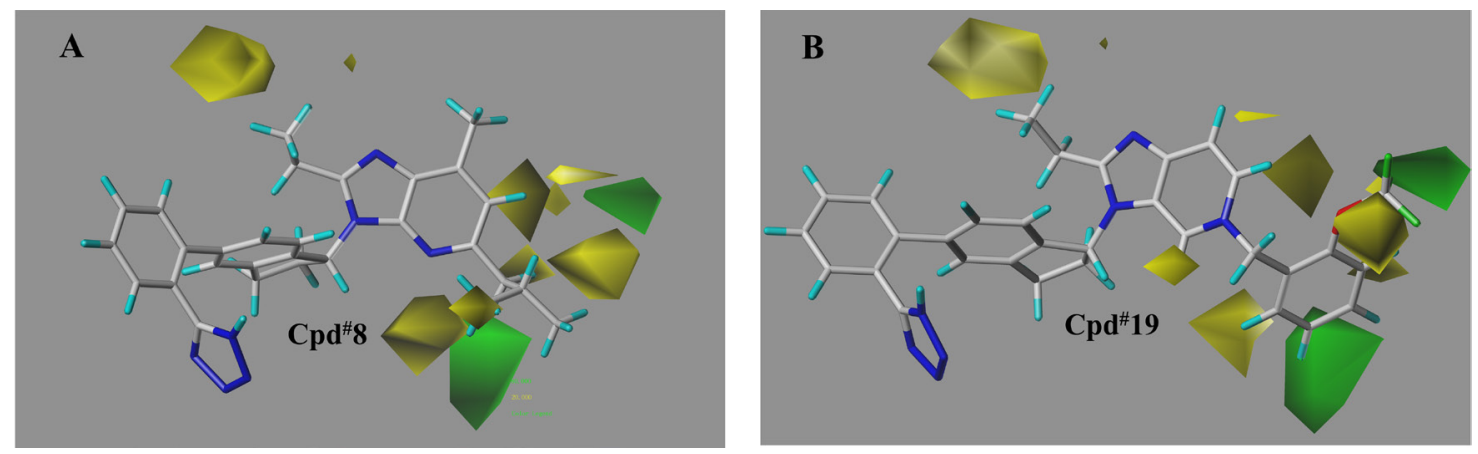

Figure 8: The steric field contour maps of representative compounds from the best CoMFA model (PPAR $\gamma$ ). The sterical favourable and unfavourable regions were represented in green and yellow, respectively. (A) compound 8, (B) compound 19 (the most active molecule).
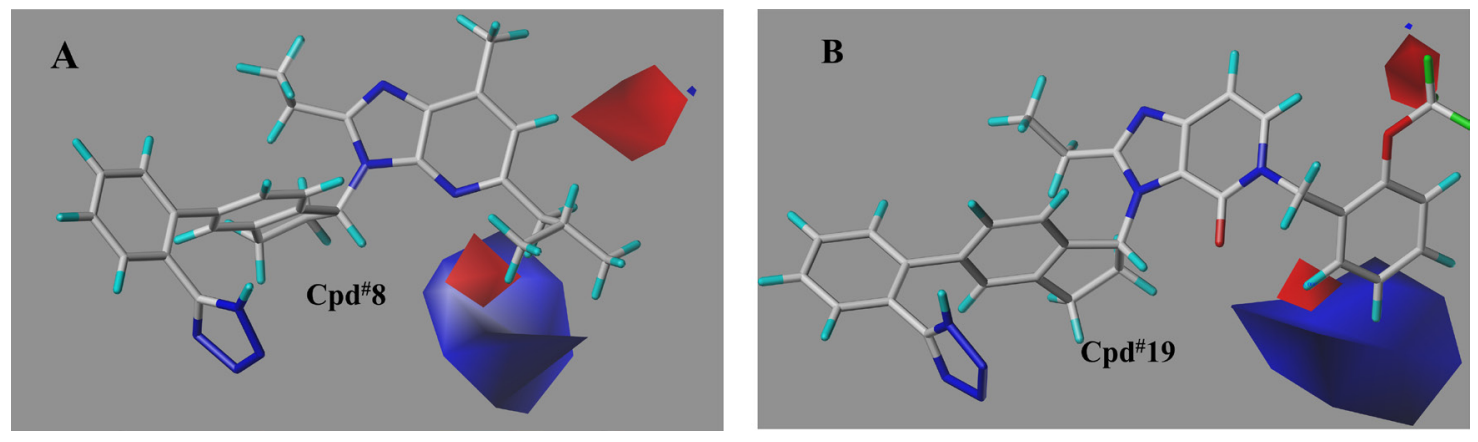

Figure 9: The electrostatic field contour maps of representative compounds from the best CoMFA model (PPAR $\gamma$ ). The blue and red contours respectively indicated that electropositive and electronegative substituents in the corresponding positions would lead to increased inhibitory activity. (A) compound 8, (B) compound 19 (the most active molecule). 


\section{AT1 model}

As interpreted in Figure 6, there was a large yellow polyhedron falling between the benzyl of the central benzimidazole ring and the imidazole group of the distal benzimidazole, indicating a greater influence on AT1 antagonistic activity. Accordingly, properly reducing the volume of the substituent would favor a lot to the activity. A green polyhedron with small size mapping the benzyl of the distal benzimidazole was hypothesized that a little increase to the bulk of the substituent on the benzyl would be beneficial. According to the CoMFA map of compound 8, a similar yellow piece overlapped the half of pyridine in the imidazo[4,5-b]pyridine, which suggested that the volumes of particular $\mathrm{R}_{2}$ part were negatively correlated to AT1 antagonistic activity. Therefore, compound 5 (15.7nM) holding an ethyl group in $\mathrm{R}_{2}$ position reduced the role in antagonism compared to compound 1 (7.6nM) with no substitution. Absolutely greater potency to 8 (1.6nM) and $9(3.5 \mathrm{nM})$ over compound 1 (7.6nM), 6 $(6.8 \mathrm{nM})$ and $3(10.2 \mathrm{nM})$ respectively just exemplified the significant role by the green block near $R_{1}$ part.

The contributions of the electrostatic field to the representative telmisartan and 8 were described in Figure 7. In details for the contour map of telmisartan, a large blue contour mapping the imidazole group of the

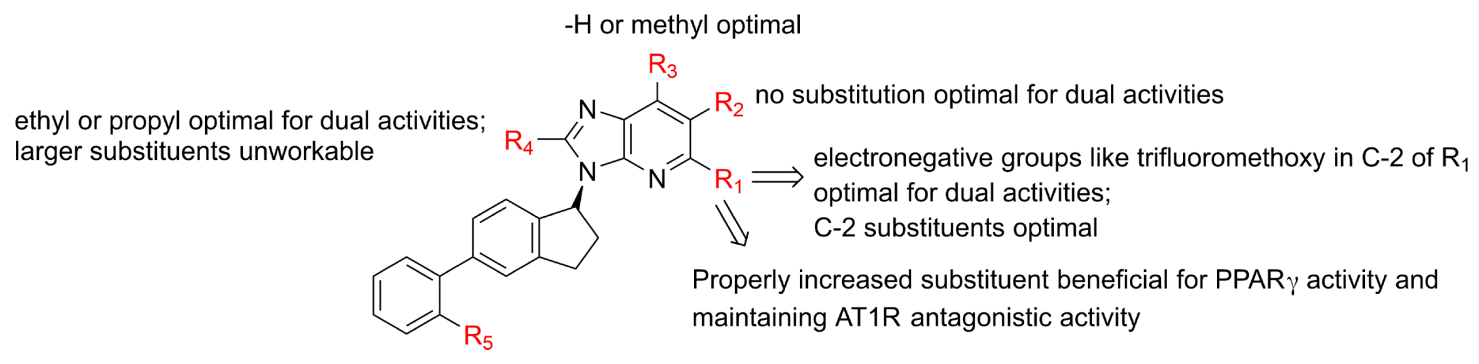

tetrazole ring or carboxylic acid

Figure 10: The SAR of imidazo- $\backslash$ pyridine derivatives from the best CoMFA models (AT1 and PPAR $\gamma$ ).
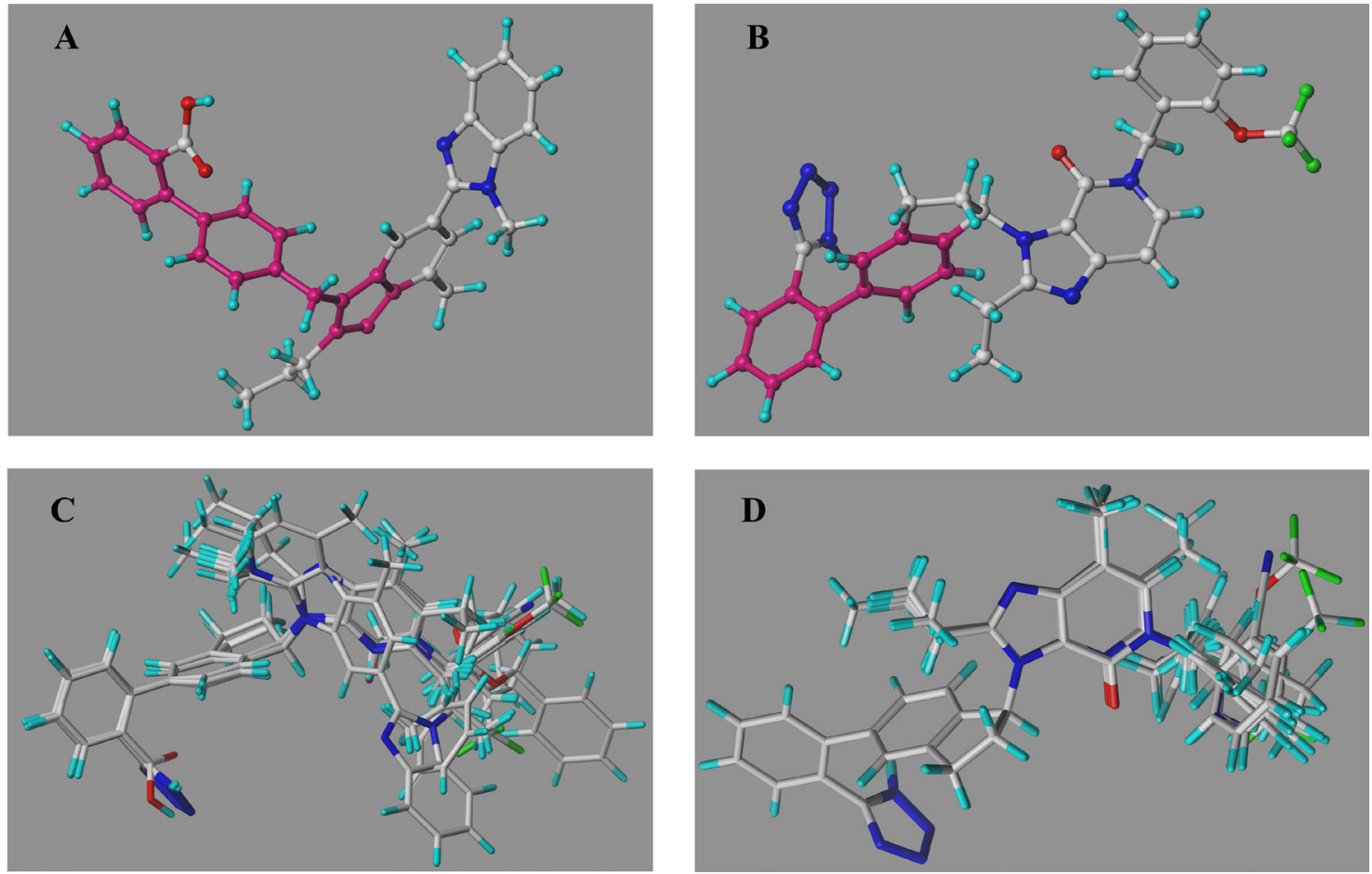

Figure 11: (A) The common substructure (magenta section) on the template of telmsartan (AT1 model) for superimposition. (B) The common substructure (magenta section) on the template of 19 (PPAR $\gamma$ model) for superimposition. (C) The molecular alignment of the training set on AT1 model. (D) The molecular alignment of the training set on PPAR $\gamma$ model. 
Table 4: The structures and predicted AT1/PPAR $\gamma$ activities of new designed molecules based on the best CoMFA models

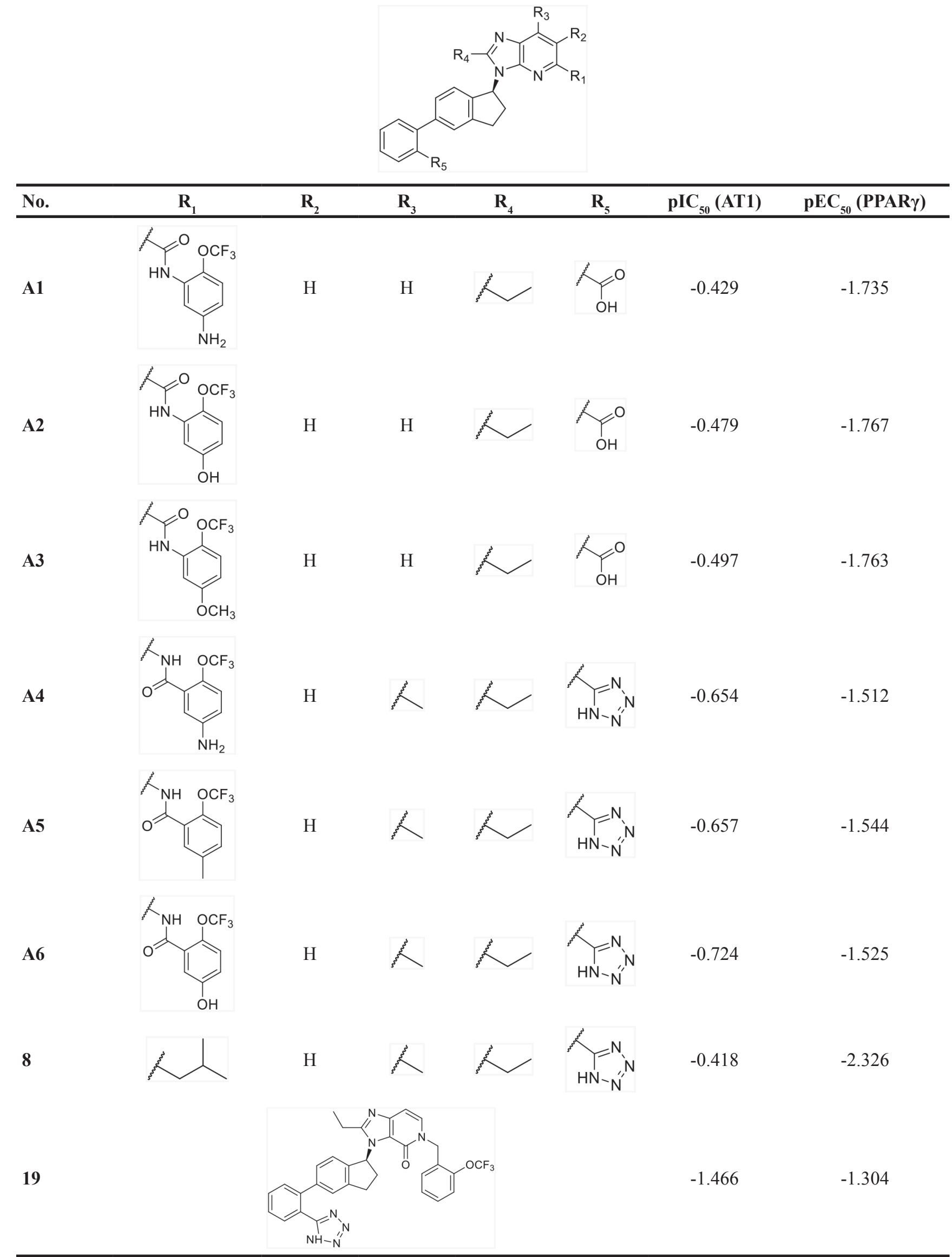


distal benzimidazole indicated that the electropositive substituent was preferred for greater effect against AT1 activity. The red parts located in the hydroxyl of carboxyl group and the C-4 position of the central benzimidazole referred that the electronegativity of the groups at this position tended to be beneficial to the activity. Taking compound 8 for further analysis, there was a big blue piece located around $R_{1}$, perfectly illustrated a better activity of compound 8,9 with isobutyl and 10 with benzyl than compounds with methyl in $\mathrm{R}_{1}$ part. Besides, compound 16 with an methyl group substituting $\mathrm{R}_{1}$ part showed clearly higher potency than compound 15,17 , 18,19 and 20 with electron withdrawing $-\mathrm{F},-\mathrm{CN},-\mathrm{CF}_{3},-$ $\mathrm{OCF}_{3}$ and $-\mathrm{F}$ group. Several red blocks around $\mathrm{R}_{2}$ moiety indicated a potentially better efficacy if with electron withdrawing groups.

\section{PPAR $\gamma$ model}

The contributions of steric and electrostatic fields to PPAR $\gamma$ partial activation were $75.4 \%$ and $24.6 \%$, respectively. So the sterical bulk played decisive role in controlling the PPAR $\gamma$ partial agonism. Figure 8 illustrated the steric contour maps of 8 and 19 towards PPAR $\gamma$ model. Seen from Figure 8A, a large green region located near $\mathrm{R}_{1}$, illustrating a better PPAR $\gamma$ activity if with properly bigger substituent, which could be verified by compound 1 (591nM), 6 (494nM), 8 (212nM) and 10 (90 nM). Around part $\mathrm{R}_{2}$, there were several small yellow blocks, indicating that groups with small volume were beneficial to the partial agonism activity. That was why $-\mathrm{H}$ was applied to $\mathrm{R}_{2}$ of imidazo[4,5-b]pyridines and imidazo[4,5-c]pyridin4-one derivatives. Additionally, a single big yellow piece situated near $\mathrm{R}_{4}$ moiety, so molecule 2 (1320nM) with n-propyl tended to be less active than 1 (591nM) with anethyl group. As observed from the study, ethyl tended to be an excellent group for potent PPAR $\gamma$ partial activation. As to the series of imidazo[4,5-c]pyridin-4-one derivatives (Figure 8B), a small green block near $-\mathrm{OCF}_{3}$ of part $\mathrm{R}_{1}$ (19) exactly explicated the higher potency than 18 with $-\mathrm{CF}_{3}$ group and 15 with $-\mathrm{F}$ substituted. An independent green piece mapped the vicinity between C-4 and C-5 position in molecule 19, assuming that the bulker group in this part would lead to increased agonistic activity.

Seen from Figure 9A, a large blue block as well as a small red piece lay around part $\mathrm{R}_{1}$ of compound 8 , supposing an increase in PPAR $\gamma$ partial activity with electron-donating groups. Additionally in Figure 9B, a relatively small red region stretched into $\mathrm{C}-2$ position of part $\mathrm{R}_{1}$, validating that molecule $11(292 \mathrm{nM})$ with $-\mathrm{H}, 15$ $(103 \mathrm{nM})$ with $-\mathrm{F}$ atom, $16(97 \mathrm{nM})$ with $-\mathrm{CH}_{3}, 17(685 \mathrm{nM})$ with $-\mathrm{CN}, 18(187 \mathrm{nM})$ with $-\mathrm{CF}_{3}$ group displayed lower activity than molecule $19(20 \mathrm{nM})$. The larger blue block in $\mathrm{C}-5$ position of part $\mathrm{R}_{1}$ assumed that the PPAR $\gamma$ partial activation may enhance if substituted with electrondonating groups. Additionally, the small red region around
6 position of $R_{1}$ (Figure 9B) might induce increased agonism by electron-withdrawing groups.

With overall analysis to imidazo- $\backslash$ pyridine derivatives, we could summarize the rules (Figure 10) as follows: (1) Increasing the $\mathrm{R}_{1}$ substituent properly will be beneficial to enhance PPAR $\gamma$ partial activity and maintain AT1R antagonistic activity; (2) The electronagative groups like trifluoromethoxy in $\mathrm{C}-2$ of part $\mathrm{R}_{1}$ caused the dual activities to increase and compounds with 2 -substituted groups tended to be more active than that of other positions; (3) $R_{2}$ substitution was improper for enhancing the activities towards AT1R antagonism and PPAR $\gamma$ partial activation; (4) ethyl or propyl in $\mathrm{R}_{4}$ was appropriate for dual activities, larger substituents were unworkable; (5) Tetrazole ring or carboxylic acid in $\mathrm{R}_{5}$ was responsible for better dual activities.

\section{Structural optimization}

Considering the structural factors towards AT1 and PPAR $\gamma$ partial activities, six molecules (Table 4) were rationally modified and screened based on the structure of compound 8. In the design process, we replaced the tetrazole ring with carboxylic acid group via the bioisostere principle and primarily substituted $R_{1}$ and $R_{3}$ parts with proper groups according to the contour maps from best AT1/PPAR $\gamma$ CoMFA models. The activities of these designed structures towards AT1 and PPAR $\gamma$ were predicted to be almost better compared to that of reported imidazo[4,5-b]pyridines and imidazo[4,5-c]pyridin-4one derivatives. The successful molecule design above illustrated that the constructed CoMFA models were highly stable and practicable to acquire novel, potential dual AT1 antagnists and PPAR $\gamma$ partial agonists.

\section{MATERIALS AND METHODS}

\section{Data set}

A set of imidazo- $\backslash$ pyridines with dual activities towards AT1 antagonism ( $\left.\mathrm{IC}_{50}: 0.49 \sim 94.1 \mathrm{nM}\right)$ and $\operatorname{PPAR} \gamma$ partial activation $\left(\mathrm{EC}_{50}: 20 \sim 3640 \mathrm{nM}\right.$ ) (Table 1) were collected from the published literatures [17, 29]. In the study, compounds with highly structural difference and no explicit activity values were excluded and not applied into the modeling. For modeling convenience, the eventual 26 molecules including telmisartan, 10 imidazo[4,5-b]pyridines and 15 imidazo[4,5-c] pyridin4-one derivatives were selected and renumbered. The values of AT1 antagonistic activity and PPAR $\gamma$ partial activation were changed into the corresponding $\mathrm{pIC}_{50}\left(-\log \mathrm{IC}_{50}\right)$ and $\mathrm{pEC}_{50}\left(-\log \mathrm{EC}_{50}\right)$ respectively as dependent variables in the study. These molecules were divided into a training set and a test set randomly with a certain proportion (4:1) aiming to include the structural 
and biological diversity [31, 32]. The former set was used to conduct the predictive CoMFA model while the latter was to validate and evaluate the predictability [33]. In this work, training sets of 21 molecules and test sets of 5 molecules respectively for CoMFA models (AT1 and PPAR $\gamma$ ) were divided.

\section{Construction and optimization of 3D structures}

Before modeling, the planar structures of these imidazo- $\backslash$ pyridine derivatives were first sketched utilizing ChemBioDraw software. Through the transformative function of "3D Geometry (Concord)" protocol implemented in SYBYL-X 2.1 software, we received the 3D structures of 26 derivatives. Afterwards, the optimized 3D conformations were obtained by "minimize" command using Powell method and Tripos force field. With the Gasteiger-Huckel Charges computation method, the process was initially performed in a simplex way and the termination value was set to gradient $0.005 \mathrm{kcal} / \mathrm{mol} \cdot \AA$ and max iterations to 1000 [34]. Other settings in this module were default.

\section{Preparation of receptors and small ligands}

Prior to docking, all preparations of receptors (AT1 and PPAR $\gamma$ ) and ligands were done via the corresponding panels implemented in Maestro v10.2 (Schrödinger, LLC, New York, 2015) [35]. The proteins for docking analysis were downloaded from RCSB Protein Data Bank (http:// www.rcsb.org/pdb/home/home.do, PDB ID: 4ZUD for AT1, 3R8A for PPAR $\gamma$ ) [17, 36]. All these compounds were docked into the receptor's active binding cavity.

As to the optimization of receptors (AT1 and PPAR $\gamma$ ), we utilized "Protein Preparation Wizard (PPW)" protocol to assign bond orders, add hydrogens, create zero-order bonds to metals, create disulfide bonds, cap termini and delete waters [37]. For the sake of optimizing the -OHs orientation and regulating the state of some amino acids, the H-bond optimization was proceeded accordingly. Energy minimization was monitored with the root mean square deviation (RMSD) set to 0.5 and the force field environment to Optimize Potentials for Liquid Simulations 2005 (OPLS_2005) [38]. Then all molecules were assigned to "LiPrep" module (Schrödinger, LLC, New York, 2015) for preparation [39, 40]. The $\mathrm{pH}$ condition for ionization generation was set to $7.0+/-2.0$ while the force field to be default OPLS_2005 as receptor preparation to avoid bonds crash.

\section{Molecular docking study}

Once the cubic grid box $(10 \times 10 \times 10 \AA$ for AT1 and $12 \times 12 \times 12 \AA$ PPAR $\gamma$ ) around the active site residues generated, the prepared molecules and proteins were submitted to Glide docking panel (Schrödinger, LLC, New York, 2015) for a perfect docking analysis [41]. According to the subsequent docking results, we were able to analyze the binding stability of a ligand-protein complex and the matching degree in the binding surface.

\section{Molecular alignment}

A perfect database alignment is crucial for deriving a reliable CoMFA model and improving the predictability $[31,42]$. "Align Database" panel in SYBYL-X 2.1 was adopted to superimpose the compounds set to the template molecule when fixed the common substructure (Figure 11). Considering the configurations in imidazo- $\backslash$ pyridine derivatives, the common moieties of these two groups in this study were determined as indicated in Figure 11A and $11 \mathrm{~B}$. The reference structures for superimposition were the most active telmisartan (AT1) and 19 (PPAR $\gamma$ ), respectively.

\section{CoMFA models}

After database alignment, the activity values of these derivatives were imported to calculate the CoMFA descriptors. CoMFA analysis is a method involving the shapes of molecules. It operated on energy values at points in space surrounding the molecules. Efforts to construct better model, $30.0 \mathrm{kcal} / \mathrm{mol}$ cutoff values for steric and electrostatic fields were assigned in creating Tripos Standard field. The energy calculations of steric (Lennard-Jones 6-12 potential) and electrostatic (Coulombic potential) fields were done automatically by the default setting, using a probe atom with van der Waals (vdW) properties of c.3 ( $\mathrm{sp}^{3}$ carbon as steric probe) and a charge of +1 (as electrostatic probe) [43]. Every molecule was set in $2 \AA$ spacing in all directions. The distance was selected as the dielectric value to control the form of the Coulombic electrostatic energy calculation [44].

When the parameters of the model calculated, Partial Least Squares (PLS) method was adopted to derive linear relationships between the bioactivity values and the CoMFA descriptors [37, 45]. PLS analysis is generally performed in two stages. The first stage is with LeaveOne-Out (LOO) method to determine how rich or complex a model is appropriate for the data values or how many components to use. LOO method means one molecule was removed from the data set and the activity was predicted by the rest [46]. Along with the optimum number of components (ONC) and no validation method, the second stage was to establish the single model that best represents the data. The cross-validated correlation coefficient $\mathrm{q}^{2}$ produced from the internal test determined the goodnessof-fit of the model [47]. This value was calculated using the following equation:

$$
\mathrm{q}^{2}=1-\frac{\sum\left(Y_{\text {pred }}-Y_{a c t}\right)^{2}}{\sum\left(Y_{\text {act }}-Y_{\text {mean }}\right)^{2}}
$$


Where $Y_{p r e d}$ and $Y_{a c t}$ refer to the predicted and actual activities of each molecule towards single target, respectively; $Y_{\text {mean }}$ is the mean activities of whole training set.

Other statistical outcomes yielding from stage two to evaluate the fitting capability, robustness and stability of the model were standard error of estimate (SEE), the conventional correlation coefficient $\left(\mathrm{r}^{2}\right)$, Fisher Test $(\mathrm{F})$ value and fields (steric and electrostatic) contributions. If $\mathrm{q}^{2}$ value is below 0.5 or $\mathrm{r}^{2}$ no greater than 0.6 , the model is indicated to be relatively poor [48]. Additionally, the closer the SEE value is to 0 and the larger value to $F$, the higher predictivity the model will be [32].

Once the CoMFA model of the training set constructed completely, the test set not involved in the modeling was used to test the external predictivity and if the model is appropriate and robust through $\mathrm{r}_{\text {pred }}{ }^{2}$ [49]. Based on the StDev*Coefficient (the standard deviation and the coefficient) contour maps, the specific impact of steric or electrostatic field contribution and distribution on potential activity would be viewed clearly [50]. All the calculations were operated in CoMFA protocol of SYBYL-X 2.1 software package.

\section{CONCLUSIONS}

Imidazo[4,5-b]pyridines and imidazo[4,5-c] pyridin4-one derivatives modified from telmisartan have been identified with dual AT1 antagonistic and PPAR $\gamma$ partial agonistic activity. In this work, the docking simulation and 3D-QSAR analysis were performed to study the SAR as well as the binding mechanism of imidazo-\pyridines with AT1 and PPAR $\gamma$ pockets. Docking results demonstrated the interaction modes and the matching degree with the binding surface. Specifically, the binding modes between imidazo-\pyridines and PPAR $\gamma$ active cavity were validated to be totally opposite from that of typical activators. From the best CoMFA models, high values for $\mathrm{q}^{2}, \mathrm{r}^{2}$ and $\mathrm{r}_{\text {pred }}{ }^{2}$ $\left(\mathrm{q}^{2}>0.5, \mathrm{r}^{2}>0.8, \mathrm{r}_{\text {pred }}^{2}>0.6\right)$ indicated satisfactory internal and external predictivity. Additionally, we concluded: (1) Increasing the $\mathrm{R}_{1}$ substituent properly will be beneficial to enhance PPAR $\gamma$ partial activity and maintain AT1R antagonistic activity; (2) The electronagative groups like trifluoromethoxy in $\mathrm{C}-2$ of part $\mathrm{R}_{1}$ caused the dual activities to increase and compounds with 2-substituted electropositive groups tended to be more active than that of other positions; (3) $\mathrm{R}_{2}$ substitution was improper for enhancing the activities towards AT1R antagonism and PPAR $\gamma$ partial activation; (4) ethyl or propyl in $\mathrm{R}_{4}$ was appropriate for dual activities, larger substituents were unworkable; (5) Tetrazole ring or carboxylic acid in $\mathrm{R}_{5}$ was responsible for better dual activities. The successful molecules design based on the contour maps of steric and electrostatic fields illustrated that the constructed CoMFA models were highly stable and practicable to acquire novel, potential dual AT1/PPAR $\gamma$ agents. Docking results were roughly coincident with the CoMFA contour maps. CoMFA models of both targets integrated with the docking analysis will be of great benefit in the optimization of potential dual AT1 antagonists and PPAR $\gamma$ partial agonists and in the identification of novel leads.

\section{Abbreviations}

AT1R, angiotensin II type 1 receptor; $\operatorname{PPAR} \gamma$, peroxisome proliferator-activated receptor $\gamma$; QSAR, Quantitative structure-activity relationships; T2DM, Type 2 diabetes mellitus; GPCR, G protein-coupled receptor; Ang II, angiotensin II; ARBs, AT1 receptor blockers; SAR, structure-activity relationship; CoMFA, Comparative Molecular Field Analysis; PDB, Protein Data Bank; PPW, Protein Preparation Wizard; RMSD, root mean square deviation; OPLS_2005, Optimize Potentials for Liquid Simulations 2005; PLS, Partial Least Squares; LOO, Leave-One-Out; ONC, optimum number of components; SEE, standard error of estimate; SP, standard-precision; StDev*Coeff, the standard deviation and the coefficient.

\section{ACKNOWLEDGMENTS}

This study was supported by the National Natural Science Foundation of China (Grant No. 21202120, $81611130090,81273361)$ and China Postdoctoral Science Foundation funded project (2012T50237).

\section{CONFLICTS OF INTEREST}

The authors declare no conflicts of interest.

\section{REFERENCES}

1. Cheng D. Prevalence, predisposition and prevention of type II diabetes. Nutr Metab (Lond). 2005; 2: 29.

2. Ardisson Korat AV, Willett WC, Hu FB. Diet, lifestyle, and genetic risk factors for type 2 diabetes: a review from the Nurses' Health Study, Nurses' Health Study 2, and Health Professionals' Follow-up Study. Curr Nutr Rep. 2014; 3: 345-54.

3. Byrne FM, Cheetham S, Vickers S, Chapman V. Characterisation of pain responses in the high fat diet/ streptozotocin model of diabetes and the analgesic effects of antidiabetic treatments. J Diabetes Res. 2015; 2015: 752481.

4. Feng X, Gao X, Jia Y, Zhang H, Pan Q, Yao Z, Yang N, Liu J, Xu Y, Wang G, Yang X. PPAR-alpha Agonist Fenofibrate Decreased Serum Irisin Levels in Type 2 Diabetes Patients with Hypertriglyceridemia. PPAR Res. 2015; 2015: 924131.

5. Maltarollo VG, Togashi M, Nascimento AS, Honorio KM. Structure-based virtual screening and discovery of New 
PPARdelta/gamma dual agonist and PPARdelta and gamma agonists. PLoS One. 2015; 10: e0118790.

6. Hermida RC, Ayala DE, Fernandez JR, Calvo C. Comparison of the efficacy of morning versus evening administration of telmisartan in essential hypertension. Hypertension. 2007; 50: 715-22.

7. Lamotte Y, Faucher N, Sancon J, Pineau O, Sautet S, Fouchet MH, Beneton V, Tousaint JJ, Saintillan Y, Ancellin N, Nicodeme E, Grillot D, Martres P. Discovery of novel indazole derivatives as dual angiotensin II antagonists and partial PPARgamma agonists. Bioorg Med Chem Lett. 2014; 24: 1098-103.

8. Benson SC, Pershadsingh HA, Ho CI, Chittiboyina A, Desai P, Pravenec M, Qi N, Wang J, Avery MA, Kurtz TW. Identification of telmisartan as a unique angiotensin II receptor antagonist with selective PPARgamma-modulating activity. Hypertension. 2004; 43: 993-1002.

9. Amano Y, Yamaguchi T, Ohno K, Niimi T, Orita M, Sakashita H, Takeuchi M. Structural basis for telmisartanmediated partial activation of PPAR gamma. Hypertens Res. 2012; 35: 715-9.

10. Park MH, Kim DH, Kim MJ, Lee EK, An HJ, Jeong JW, Kim HR, Kim SJ, Yu BP, Moon HR, Chung HY. Effects of MHY908, a New Synthetic PPARalpha/gamma Dual Agonist, on Inflammatory Responses and Insulin Resistance in Aged Rats. J Gerontol A Biol Sci Med Sci. 2016; 71: 300-9.

11. Hanf R, Millatt LJ, Cariou B, Noel B, Rigou G, Delataille P, Daix V, Hum DW, Staels B. The dual peroxisome proliferator-activated receptor alpha/delta agonist GFT505 exerts anti-diabetic effects in $\mathrm{db} / \mathrm{db}$ mice without peroxisome proliferator-activated receptor gammaassociated adverse cardiac effects. Diab Vasc Dis Res. 2014; 11: 440-7.

12. Encinar JA, Fernandez-Ballester G, Galiano-Ibarra V, Micol V. In silico approach for the discovery of new PPARgamma modulators among plant-derived polyphenols. Drug Des Devel Ther. 2015; 9: 5877-95.

13. Silva JC, Cesar FA, de Oliveira EM, Turato WM, Tripodi GL, Castilho G, Machado-Lima A, de Las Heras B, Bosca L, Rabello MM, Hernandes MZ, Pitta MG, Pitta IR, et al. New PPARgamma partial agonist improves obesity-induced metabolic alterations and atherosclerosis in LDLr(-/-) mice. Pharmacol Res. 2016; 104: 49-60.

14. Gao Q, Hanh J, Varadi L, Cairns R, Sjostrom H, Liao VW, Wood P, Balaban S, Ong JA, Lin HY, Lai F, Hoy AJ, Grewal $\mathrm{T}$, et al. Identification of dual PPARalpha/gamma agonists and their effects on lipid metabolism. Bioorg Med Chem. 2015; 23: 7676-84.

15. Fujita T, Sugiyama $\mathrm{Y}$, Taketomi S, Sohda $\mathrm{T}$, Kawamatsu Y, Iwatsuka H, Suzuoki Z. Reduction of insulin resistance in obese and/or diabetic animals by 5-[4-(1-methylcyclohexylmethoxy)benzyl]-thiazolidine2,4-dione (ADD-3878, U-63,287, ciglitazone), a new antidiabetic agent. Diabetes. 1983; 32: 804-10.
16. Soccio RE, Chen ER, Lazar MA. Thiazolidinediones and the promise of insulin sensitization in type 2 diabetes. Cell Metab. 2014; 20: 573-91.

17. Casimiro-Garcia A, Filzen GF, Flynn D, Bigge CF, Chen J, Davis JA, Dudley DA, Edmunds JJ, Esmaeil N, Geyer A, Heemstra RJ, Jalaie M, Ohren JF, et al. Discovery of a series of imidazo[4,5-b]pyridines with dual activity at angiotensin II type 1 receptor and peroxisome proliferatoractivated receptor-gamma. J Med Chem. 2011; 54: 4219-33.

18. Moravek MB, Ward EA, Lebovic DI. Thiazolidinediones as therapy for endometriosis: a case series. Gynecol Obstet Invest. 2009; 68: 167-70.

19. Mizuno CS, Chittiboyina AG, Shah FH, Patny A, Kurtz TW, Pershadsingh HA, Speth RC, Karamyan VT, Carvalho PB, Avery MA. Design, synthesis, and docking studies of novel benzimidazoles for the treatment of metabolic syndrome. J Med Chem. 2010; 53: 1076-85.

20. Nissen SE, Wolski K. Effect of rosiglitazone on the risk of myocardial infarction and death from cardiovascular causes. N Engl J Med. 2007; 356: 2457-71.

21. Takezako T, Unal H, Karnik SS, Node K. StructureFunction Basis of Attenuated Inverse Agonism of Angiotensin II Type 1 Receptor Blockers for Active-State Angiotensin II Type 1 Receptor. Mol Pharmacol. 2015; 88: 488-501.

22. Liu H, Mao P, Wang J, Wang T, Xie CH. Azilsartan, an angiotensin II type 1 receptor blocker, attenuates tertbutyl hydroperoxide-induced endothelial cell injury through inhibition of mitochondrial dysfunction and antiinflammatory activity. Neurochem Int. 2016; 94:48-56.

23. Singh KD, Muthusamy K. Molecular modeling, quantum polarized ligand docking and structure-based 3D-QSAR analysis of the imidazole series as dual AT(1) and ET(A) receptor antagonists. Acta Pharmacol Sin. 2013; 34: 1592-606.

24. Padda RS, Shi Y, Lo CS, Zhang SL, Chan JS. Angiotensin-(1-7): A Novel Peptide to Treat Hypertension and Nephropathy in Diabetes? J Diabetes Metab. 2015; 6.

25. Zhang H, Unal H, Gati C, Han GW, Liu W, Zatsepin NA, James D, Wang D, Nelson G, Weierstall U, Sawaya MR, $\mathrm{Xu}$ Q, Messerschmidt M, et al. Structure of the Angiotensin receptor revealed by serial femtosecond crystallography. Cell. 2015; 161: 833-44.

26. Miao L, Chen W, Zhou L, Wan H, Gao B, Feng Y. Impact of Angiotensin I-converting Enzyme Inhibitors and Angiotensin II Type-1 Receptor Blockers on Survival of Patients with NSCLC. Sci Rep. 2016; 6: 21359.

27. Mahmood A, Pulakat L. Differential Effects of betaBlockers, Angiotensin II Receptor Blockers, and a Novel AT2R Agonist NP-6A4 on Stress Response of NutrientStarved Cardiovascular Cells. PLoS One. 2015; 10: e0144824.

28. Sigmund CD. A clinical link between peroxisome proliferator-activated receptor gamma and the 
renin-angiotensin system. Arterioscler Thromb Vasc Biol. 2013; 33: 676-8.

29. Casimiro-Garcia A, Heemstra RJ, Bigge CF, Chen J, Ciske FA, Davis JA, Ellis T, Esmaeil N, Flynn D, Han S, Jalaie M, Ohren JF, Powell NA. Design, synthesis, and evaluation of imidazo[4,5-c]pyridin-4-one derivatives with dual activity at angiotensin II type 1 receptor and peroxisome proliferator-activated receptor-gamma. Bioorg Med Chem Lett. 2013; 23: 767-72.

30. Lang CA, Ray SS, Liu M, Singh AK, Cuny GD. Discovery of LRRK2 inhibitors using sequential in silico joint pharmacophore space (JPS) and ensemble docking. Bioorg Med Chem Lett. 2015; 25: 2713-9.

31. Thai KM, Bui QH, Tran TD, Huynh TN. QSAR modeling on benzo[c]phenanthridine analogues as topoisomerase I inhibitors and anti-cancer agents. Molecules. 2012; 17: 5690-712.

32. Thareja S, Rajpoot T, Verma SK. Generation of comparative pharmacophoric model for steroidal 5alpha-reductase I and II inhibitors: A 3D-QSAR study on 6-azasteroids. Steroids. 2015; 95: 96-103.

33. Ma S, Zeng G, Fang D, Wang J, Wu W, Xie W, Tan S, Zheng K. Studies of N(9)-arenthenyl purines as novel DFG-in and DFG-out dual Src/Abl inhibitors using 3D-QSAR, docking and molecular dynamics simulations. Mol Biosyst. 2015; 11: 394-406.

34. Chen Y, Cai X, Jiang L, Li Y. Prediction of octanol-air partition coefficients for polychlorinated biphenyls (PCBs) using 3D-QSAR models. Ecotoxicol Environ Saf. 2016; 124: 202-12.

35. Honmore VS, Kandhare AD, Kadam PP, Khedkar VM, Sarkar D, Bodhankar SL, Zanwar AA, Rojatkar SR, Natu AD. Isolates of Alpinia officinarum Hance as COX-2 inhibitors: Evidence from anti-inflammatory, antioxidant and molecular docking studies. Int Immunopharmacol. 2016; 33: 8-17.

36. Zhang H, Unal H, Desnoyer R, Han GW, Patel N, Katritch V, Karnik SS, Cherezov V, Stevens RC. Structural Basis for Ligand Recognition and Functional Selectivity at Angiotensin Receptor. J Biol Chem. 2015; 290: 29127-39.

37. Goyal M, Dhanjal JK, Goyal S, Tyagi C, Hamid R, Grover A. Development of dual inhibitors against Alzheimer's disease using fragment-based QSAR and molecular docking. Biomed Res Int. 2014; 2014: 979606.

38. Tripuraneni NS, Azam MA. A combination of pharmacophore modeling, atom-based 3D-QSAR, molecular docking and molecular dynamics simulation studies on PDE4 enzyme inhibitors. J Biomol Struct Dyn. 2015: 1-41.

39. Kaczor AA, Targowska-Duda KM, Patel JZ, Laitinen T, Parkkari T, Adams Y, Nevalainen TJ, Poso A. Comparative molecular field analysis and molecular dynamics studies of alpha/beta hydrolase domain containing 6 (ABHD6) inhibitors. J Mol Model. 2015; 21: 250.
40. Subhani S, Jamil K. Molecular docking of chemotherapeutic agents to CYP3A4 in non-small cell lung cancer. Biomed Pharmacother. 2015; 73: 65-74.

41. Harini K, Sowdhamini R. Computational Approaches for Decoding Select Odorant-Olfactory Receptor Interactions Using Mini-Virtual Screening. PLoS One. 2015; 10: e0131077.

42. Vitorovic-Todorovic MD, Cvijetic IN, Juranic IO, Drakulic BJ. The 3D-QSAR study of 110 diverse, dual binding, acetylcholinesterase inhibitors based on alignment independent descriptors (GRIND-2). The effects of conformation on predictive power and interpretability of the models. J Mol Graph Model. 2012; 38: 194-210.

43. Kakarla P, Inupakutika M, Devireddy AR, Gunda SK, Willmon TM, Ranjana KC, Shrestha U, Ranaweera I, Hernandez AJ, Barr S, Varela MF. 3d-Qsar and Contour Map Analysis of Tariquidar Analogues as Multidrug Resistance Protein-1 (Mrp1) Inhibitors. Int J Pharm Sci Res. 2016; 7: 554-72.

44. Hassan HM, Elnagar AY, Khanfar MA, Sallam AA, Mohammed R, Shaala LA, Youssef DT, Hifnawy MS, El Sayed KA. Design of semisynthetic analogues and 3D-QSAR study of eunicellin-based diterpenoids as prostate cancer migration and invasion inhibitors. Eur $\mathrm{J}$ Med Chem. 2011; 46: 1122-30.

45. Zhou Z, Cheng C, Li Y. Structure-based design and optimization of antihypertensive peptides to obtain high inhibitory potency against both renin and angiotensin I-converting enzyme. SAR QSAR Environ Res. 2015; 26: 1001-16.

46. Borisa A, Bhatt H. 3D-QSAR (CoMFA, CoMFA-RG, CoMSIA) and molecular docking study of thienopyrimidine and thienopyridine derivatives to explore structural requirements for aurora-B kinase inhibition. Eur J Pharm Sci. 2015; 79: 1-12.

47. Liu HC, Tang SZ, Lu S, Ran T, Wang J, Zhang YM, Xu AY, Lu T, Chen YD. Studies on [5,6]-Fused Bicyclic Scaffolds Derivatives as Potent Dual B-RafV600E/KDR Inhibitors Using Docking and 3D-QSAR Approaches. Int J Mol Sci. 2015; 16: 24451-74.

48. Du QR, Li DD, Pi YZ, Li JR, Sun J, Fang F, Zhong WQ, Gong HB, Zhu HL. Novel 1,3,4-oxadiazole thioether derivatives targeting thymidylate synthase as dual anticancer/antimicrobial agents. Bioorg Med Chem. 2013; 21: 2286-97.

49. Jiang X, Wang Y, Zhu H, Wang Y, Zhao M, Zhao S, Wu J, Li S, Peng S. Modifying tetramethyl-nitrophenyl-imidazoline with amino acids: design, synthesis, and 3D-QSAR for improving inflammatory pain therapy. Drug Des Devel Ther. 2015; 9: 2329-42.

50. Sharma MC. Prospective QSAR-based prediction models with pharmacophore studies of oxadiazole-substituted alpha-isopropoxy phenylpropanoic acids on with dual activators of PPARalpha and PPARgamma. Interdiscip Sci. 2014. 